\title{
Image analysis application for the study of activated sludge floc size during the treatment of synthetic and real fishery wastewaters
}

\author{
Daniela P. Mesquita • Roberta R. Ribeiro • \\ António L. Amaral • Eugénio C. Ferreira • \\ Maria Alice Z. Coelho
}

Received: 16 June 2010 / Accepted: 14 March 2011 /Published online: 8 April 2011

(C) Springer-Verlag 2011

\begin{abstract}
Background, aim, and scope Fishery wastewater treatment can be compromised due to seasonal production. The use of sequencing batch reactors is not completely successful, despite flexibility being one of the principal advantages. Most research on activated sludge is performed using synthetic wastewater to ensure a stable and constant feed. The current work compared biomass morphology and settling ability using image analysis of synthetic and real fishery wastewaters, with and without $\mathrm{NaCl}$ addition.

Results The final effluent presented higher turbidity for both wastewaters after $\mathrm{NaCl}$ addition, and lower SVI values. For synthetic wastewater, $\mathrm{NaCl}$ addition led to the total aggregates' area (TA) increase from 1.46 to $2.09 \mathrm{~mm}^{2} /$ $\mu \mathrm{L}$, alongside the growth of intermediate aggregates into larger aggregates. The addition of $\mathrm{NaCl}$ to the fishery wastewater led to a decrease of the TA from 4.43 to $1.72 \mathrm{~mm}^{2} / \mu \mathrm{L}$. The biomass composition decreased in larger
\end{abstract}

Responsible editor: Thomas Braunbeck

R. R. Ribeiro • M. A. Z. Coelho $(\bowtie)$

Departamento de Engenharia Bioquímica, Escola de Química, Universidade Federal do Rio de Janeiro,

Rio de Janeiro 21949-900, Brazil

e-mail: alice@eq.ufrj.br

D. P. Mesquita • A. L. Amaral • E. C. Ferreira IBB-Institute for Biotechnology and Bioengineering, Centre of Biological Engineering, Universidade do Minho, Campus de Gualtar,

4710-057 Braga, Portugal

\section{A. L. Amaral}

Instituto Superior de Engenharia de Coimbra, Instituto Politécnico de Coimbra,

Rua Pedro Nunes, Quinta da Nora,

3030-199 Coimbra, Portugal and intermediate structures, opposite to the smaller aggregates' area percentage increase.

Discussion $\mathrm{NaCl}$ addition to synthetic wastewater incited flocculation increasing sludge settling ability. A slight aggregate disruption was responsible for a turbidity increase. A strong deflocculation was identified in fishery wastewater with $\mathrm{NaCl}$ from the decrease of intermediate and large aggregates. This contrasted with pinpoint flocs release, which increased the turbidity levels.

Conclusions, recommendations, and perspectives It could be established that synthetic wastewater biomass flocculation and fishery wastewater biomass deflocculation, observed during $0.5 \% \mathrm{NaCl}$ experiments, were related to sludge settling and effluent turbidity changes. Furthermore, the biomass changes obtained with synthetic wastewater cannot be extrapolated to fishery wastewater.

Keywords SBR - Synthetic wastewater · Fishery wastewater $\cdot$ Settling $\cdot$ Image analysis $\cdot$ Aggregates $\cdot$ Salinity

\section{Background, aim, and scope}

Sequencing batch reactors (SBR) are one of the most effective methods for treating wastewater, allowing the control of filamentous bacteria and flexibility of operation cycles (Souza et al. 2008; Rene et al. 2007; Moussa et al. 2006; Uygur 2006; Uygur and Kargi 2004). The bioreactors are compact, uncomplicated to operate, and provide higher treatment efficiency compared to conventional activated sludge systems. The fish processing sector generates saline wastewaters which reduce biological treatment efficiencies and population structure (Moussa et al. 2006), mainly from seawater release during fish unloading (Lefebvre and 
Moletta 2006). Fisheries produce wastewaters rich in nitrogen, organic matter, and $\mathrm{NaCl}$ (Antileo et al. 1997), and it is the high percentage of $\mathrm{NaCl}$ that compromises the treatment. The (i) limited biomass adaptation, (ii) sensitivity to ion concentration changes, (iii) reduced degradation rates, (iv) high suspended solid concentrations causing high effluent turbidity, and (v) formation of low-settling activated sludge aggregates are well-known problems (Kargi and Dinçer 1999; Dinçer and Kargi 1999; Panswad and Anan 1999).

Protozoa are considered good indicators of the treatment quality in activated sludge as they are sensitive to physical, chemical, and operational processes (Ginoris et al. 2007). The effluent turbidity can be influenced particularly by low protozoa concentrations, which may be induced by salinity "shocks" ( $\mathrm{Ng}$ et al. 2005). High salinity also leads to a decrease on the microbial population diversity and may decrease sludge settling characteristics (Moussa et al. 2006). However, acclimation of the sludge to high salinity conditions is possible. Acclimation is defined as the exposure of non-salt-adapted microorganisms to increasing $\mathrm{NaCl}$ concentrations in order to achieve an acceptable treatment at a given salt concentration. This adaptation depends on the type and growth ability of microorganisms, on the degree of increase, and absolute $\mathrm{NaCl}$ concentration, as the microorganisms' adaptation is limited when $\mathrm{NaCl}$ concentration is very high (Lefebvre and Moletta 2006; Dinçer and Kargi 2001). Also, gradual salinity increases have less effect than the sudden increases (Oren and Gurevich 1992).

Image analysis is a valuable method to characterize the biomass within bioreactors (da Motta et al. 2001). Microscopic image analysis procedures are successfully used for morphological characterization of microbial aggregates and evaluation of filamentous bacteria contents to correlate such parameters with biomass settling properties (Mesquita et al. 2009a). Recent developments on floc structure analysis associated to microscopy techniques give access to an indepth analysis of structural information (Jarvis et al. 2005). The characteristics of bioaggregates, including their internal structure, chemical composition, and microbial ecology, determine the transport properties and chemical reaction rates and affect the overall performance of treatment processes involving aggregates (Chu and Lee 2004). Other morphological, physical, and chemical factors, including particle surface properties, size, extracellular polymeric substances, and flocculating ability were also referred as affecting factors in solid-liquid separation processes (Li and Ganczarczyk 1991; Wilén et al. 2003; Li and Yang 2007).

Recently, a great deal of attention has been focused on the research of activated sludge processes, where the solidliquid separation phase is frequently considered of critical importance, due to the different problems that severely affect sludge compaction and settling. Mesquita et al. (Mesquita et al. 2009a, b) developed an image analysis program in order to detect bulking events, proving that the developed image analysis methodology is adequate for a continuous examination of the morphological changes in microbial aggregates and subsequent estimation of the sludge settling properties. In fact, the obtained results demonstrated that the developed image analysis methodology is a feasible method for the continuous monitoring of activated sludge systems and disturbances identification. For example, this technique was used to study the effect of different $\mathrm{NaCl}$ concentrations on the aggregates' characteristics in a SBR unit (Mesquita et al. 2009c), and $\mathrm{NaCl}$ incited a strong aggregate deflocculation leading to a heavy loss of biomass.

No studies have compared synthetic and fishery wastewaters with respect to activated sludge floc contents, a determinant factor in solid-liquid separation. The present work reports on biomass morphology, sludge settling, and effluent turbidity during SBR treatment of synthetic and fishery wastewaters.

\section{Materials and methods}

\subsection{Experimental setup}

A SBR $(50 \mathrm{~L})$ equipped with a controllable feed pump, air supply, and sensors (wastewater level, oxidation-reduction potential, $\mathrm{pH}$, and dissolved oxygen) was fed with wastewater at a flow rate of $5 \mathrm{Lh}^{-1}$. For data acquisition and control, a supervisory system (FIX-DMACS, Intellution, v.6.15) was employed. The reactor operated during 30 days (including acclimation) for each experiment, with a hydraulic retention time of $10 \mathrm{~h}$ and a food to microorganisms ratio $(\mathrm{F} / \mathrm{M})$ ranging between $0.28-0.3 \mathrm{~g} \mathrm{COD} / \mathrm{g}$ TSS day for the synthetic wastewater experiment and between $0.4-0.5 \mathrm{~g}$ $\mathrm{COD} / \mathrm{g}$ TSS day for the real fishery wastewater experiment. The temperature inside the reactor was $23 \pm 2^{\circ} \mathrm{C}$.

\subsection{Wastewater composition}

Synthetic wastewater was prepared with de-mineralized water with the following composition (milligrams per liter): $\mathrm{NH}_{4} \mathrm{Cl}, 76.1 ; \mathrm{C}_{6} \mathrm{H}_{12} \mathrm{O}_{6}, 300 ; \mathrm{MgSO}_{4} \cdot 7 \mathrm{H}_{2} \mathrm{O}, 16.7$; $\mathrm{NaHCO}_{3}, 243.3 ; \mathrm{Na}_{2} \mathrm{CO}_{3}, 162.2 ; \mathrm{Na}_{2} \mathrm{HPO}_{4} \cdot 12 \mathrm{H}_{2} \mathrm{O}, 46.2$; $\mathrm{CaCl}_{2} \cdot 7 \mathrm{H}_{2} \mathrm{O}$, 4.7; and $\mathrm{KCl}, 4.7$. The $\mathrm{NaCl}$ concentration varied between $0 \%$ and $0.5 \%(w / v)$. The sludge, kindly provided by PETROBRAS S.A., was maintained in the reactor throughout the whole experimental period, and the sludge concentration was approximately $2.5 \mathrm{~g} \mathrm{TSS} \mathrm{L}^{-1}$.

The fishery wastewater and sludge were provided by PEPSI Co., São Gonçalo, RJ, Brazil, processing sardines 
(120 t/day) and tunas (15 t/day) with a sludge concentration of $5 \mathrm{~g} \mathrm{TSS} \mathrm{L}^{-1}$. During reactor operation, no significant biomass growth was detected, i.e., a constant ratio between volatile suspended solids (VSS) and total suspended solids (TSS) was found. A similar situation has been described by other authors employing the same experimental setup (Seixo et al. 2004; Souza et al. 2008). The effluent salinity was measured, ranging between $0.1 \%$ (without $\mathrm{NaCl}$ addition) and $0.5 \%(\mathrm{NaCl}$ addition in $w / v)$. The study with fishery wastewater was performed in two different periods, meaning that the composition was different. Synthetic and fishery wastewater compositions are presented in Table 1 . The chemical oxygen demand (COD) and $\mathrm{N}-\mathrm{NH}_{4}{ }^{+}$measurements followed the standard methods, and three replicates per sample were determined (APHA et al. 1989).

\subsection{Strategy description}

To study the reactor behavior for both wastewaters, a biomass acclimation was performed for at least 15 days, allowing the microorganisms to adapt. Thus, in order to guarantee high-quality SBR performance, sludge acclimation for each $\mathrm{NaCl}$ concentration was performed until the system reached steady-state conditions. The strategy implemented for this work was based on a previous study, where a discrete fill strategy consisting of symmetric pulses for wastewater and oxygen supply was favored (Coelho et al. 2000). For both wastewaters and each experiment, operating cycles consisted of $6 \mathrm{~h}$ encompassing filling, reaction, and settling phases. During the discrete fill and throughout a total period of $3.5 \mathrm{~h}$, a sequence of aerobic and anoxic stages (30 min each) was performed, allowing for low substrate levels and decreased cell inhibition. Afterwards, the reaction step took place during $2 \mathrm{~h}$. Finally, the biomass was allowed to settle for a period of $0.5 \mathrm{~h}$, followed by supernatant removal.

\subsection{SVI and turbidity measurements}

The sludge height variation with time, $\mathrm{h}(\mathrm{t})$, was monitored for $30 \mathrm{~min}$ in a 1-L settling cylinder after each SBR cycle. TSS was given by weight and used to determine the sludge volume index (SVI) (APHA et al. 1989). The SVI is largely used for sludge settling ability evaluation, varying inversely with the sludge ability to settle, making it an interesting parameter within the system efficiency assessment. Effluent turbidity was determined in the supernatant through a HACH DR4000-UV spectrophotometer at $860 \mathrm{~nm}(\mathrm{HACH}$, Colorado, USA) after $30 \mathrm{~min}$ of biomass settling.

\subsection{Image acquisition, processing, and analysis}

At the end of each cycle, samples were collected from the reactor to carry out the image acquisition procedure. For the aggregates' image acquisition, three slides were used for increased accuracy on the determination of the sludge characteristics. Images of the reactor biomass from the synthetic and fishery wastewater experiments are presented in Fig. 1. A volume of $50 \mu \mathrm{L}$ was taken to a slide and covered with a $20 \times 20$-mm cover slip for visualization and image acquisition in bright field microscopy. Around 100 images $(2,048 \times 1,536$ pixels in 8 bits $)$ were acquired per sample, through the visualization on a Nikon Eclipse 200 microscope (Nikon Corporation, Tokyo), with a total magnification of $\times 40$, coupled to a Nikon Coolpix 990 RGB camera (Nikon Corporation, Tokyo). Aggregated bacteria morphological descriptors were determined using software routines developed in ImageJ (NIH, USA) and Matlab 7.3 (The Mathworks, Natick) (Amaral 2003; Amaral and Ferreira 2005). ImageJ was used for image processing to obtain the binary images of the aggregates from the grayscale images, comprising image pre-treatment, image segmentation, and debris elimination. Matlab was used to determine the aggregates' morphological parameters, described below.

The image pre-processing stage consisted of the enhancement of the grayscale images by background removal. A background subtraction was performed, minimizing background light differences, and aggregates were further enhanced. Next, a segmentation step comprised the conversion of the grayscale image to a binary image followed by the elimination of small debris (Amaral and Ferreira 2005). Figure 2 represents an example of original and final binary images obtained from the program.
Table 1 Synthetic and fishery wastewater compositions, SVI, turbidity, and biomass total aggregates' area with $(0.5 \%)$ and without $\mathrm{NaCl}$ addition

\begin{tabular}{|c|c|c|c|c|}
\hline & \multicolumn{2}{|c|}{ Synthetic wastewater } & \multicolumn{2}{|c|}{ Fishery wastewater } \\
\hline & $0 \%$ & $0.5 \%$ & $0.1 \%$ & $0.5 \%$ \\
\hline COD $(\mathrm{mg} / \mathrm{L})$ & $300.73 \pm 4.12$ & $320 \pm 9.77$ & $940.25 \pm 9.65$ & $1,173.00 \pm 4.33$ \\
\hline $\mathrm{N}-\mathrm{NH}_{4}^{+}(\mathrm{mg} / \mathrm{L})$ & $22.99 \pm 1.55$ & $22.78 \pm 0.51$ & $29.15 \pm 5.25$ & $209.07 \pm 8.15$ \\
\hline SVI (mL $\left.\mathrm{gTSS}^{-1}\right)$ & $128.18 \pm 8.18$ & $58.57 \pm 1.42$ & $71.55 \pm 11.77$ & $47.50 \pm 15.78$ \\
\hline Turbidity (FAU) & $9.50 \pm 1.50$ & $11.50 \pm 0.5$ & $48.21 \pm 1.96$ & $53.50 \pm 0.62$ \\
\hline $\mathrm{TA}\left(\mathrm{mm}^{2} / \mu \mathrm{L}\right)$ & $1.46 \pm 0.03$ & $2.09 \pm 0.05$ & $4.43 \pm 0.02$ & $1.72 \pm 0.04$ \\
\hline
\end{tabular}


Fig. 1 a An image obtained without $\mathrm{NaCl}$ addition and $\mathbf{b}$ an image obtained with $0.5 \% \mathrm{NaCl}$ addition for synthetic wastewater; c an image obtained without $\mathrm{NaCl}$ addition and $\mathbf{d}$ an image obtained with $0.5 \% \mathrm{NaCl}$ addition for fishery wastewater
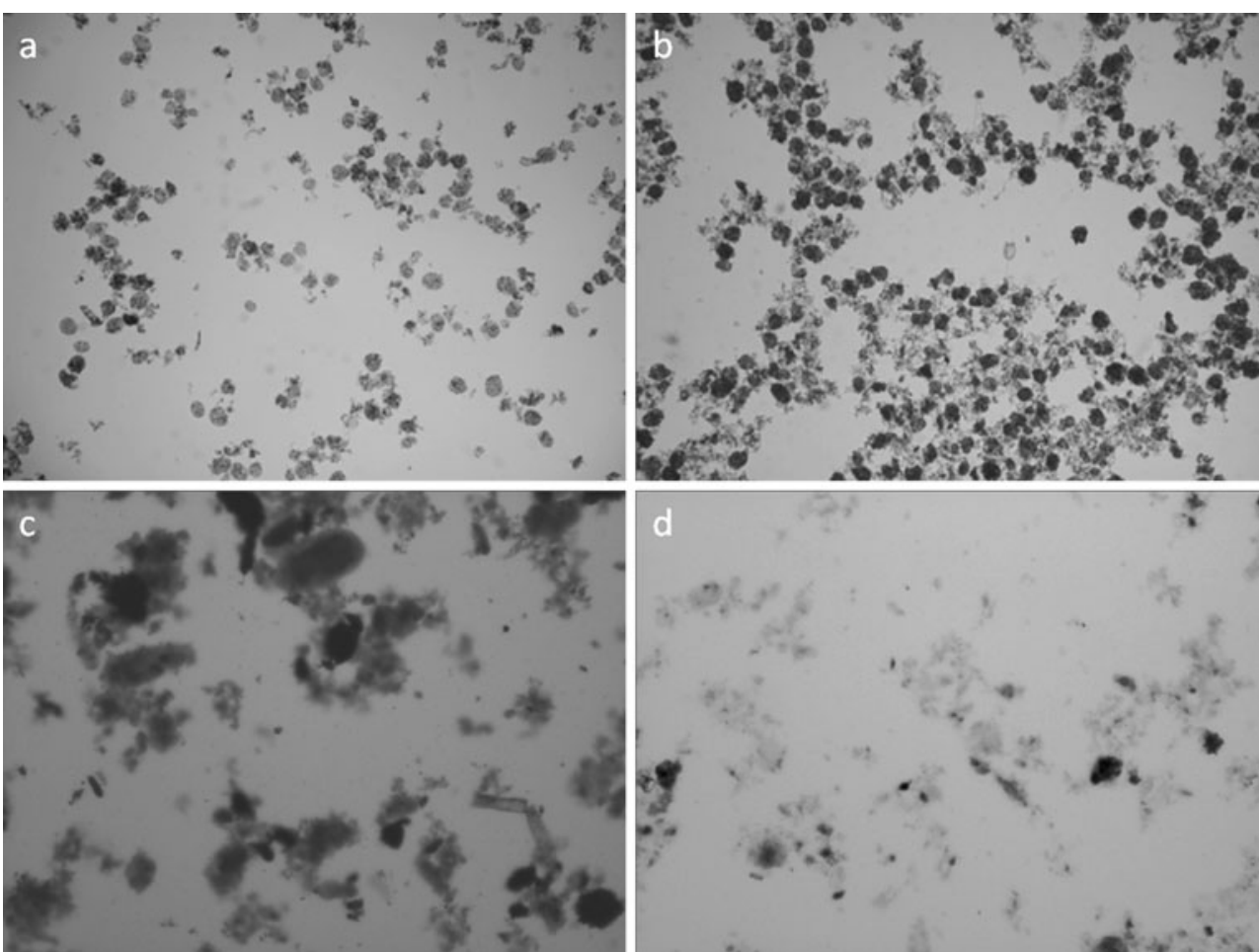

Previous research works on activated sludge systems by image analysis procedures already allowed the determination of several key parameters providing valuable information about the sludge status, and to predict deflocculation phenomena (Amaral and Ferreira 2005). Regarding the present work, the number of aggregates was calculated by the total number of aggregates not cut off by the images' boundaries. The aggregates' area was given by the number of pixels belonging to an object converted to metric units, and the total aggregates' area by the cumulative area of all the aggregates. In previous studies, the usefulness of evaluating the aggregates at different size classes has already been found (Mesquita et al. 2009a; Amaral and Ferreira 2005). In this work, the aggregates were divided into three classes with respect to their equivalent diameter $\left(D_{\text {eq }}\right)$ : below $0.01 \mathrm{~mm}$, between $0.01-0.1 \mathrm{~mm}$, and above $0.1 \mathrm{~mm}$ (Mesquita et al. 2009c). The larger aggregates were considered to be normal aggregates (contained within the aggregates above $0.1 \mathrm{~mm}$ in equivalent diameter); the intermediate class was composed of small aggregates (between 0.01 and $0.1 \mathrm{~mm}$ in equivalent diameter), and the smaller class configured pinpoint flocs (aggregates below $0.01 \mathrm{~mm}$ in equivalent diameter).

The $D_{\text {eq }}$ was determined based on the aggregates' area (Area) and on the calibration factor $\left(F_{\text {Cal }}\right)$ as follows:

$D_{\text {eq }}=2 F_{\text {Cal }} \sqrt{\frac{\text { Area }}{\pi}}$

Where the $F_{\text {Cal }}$ is a calibration factor obtained using a micrometer in order to change the pixel unit to micrometers $\left(\mu \mathrm{m}\right.$ pixel $\left.^{-1}\right)$.

\section{Results}

Table 1 displays the composition of synthetic and fishery wastewaters without and with $\mathrm{NaCl}$ addition in terms of
Fig. 2 Original (a) and binary (b) images obtained from the program
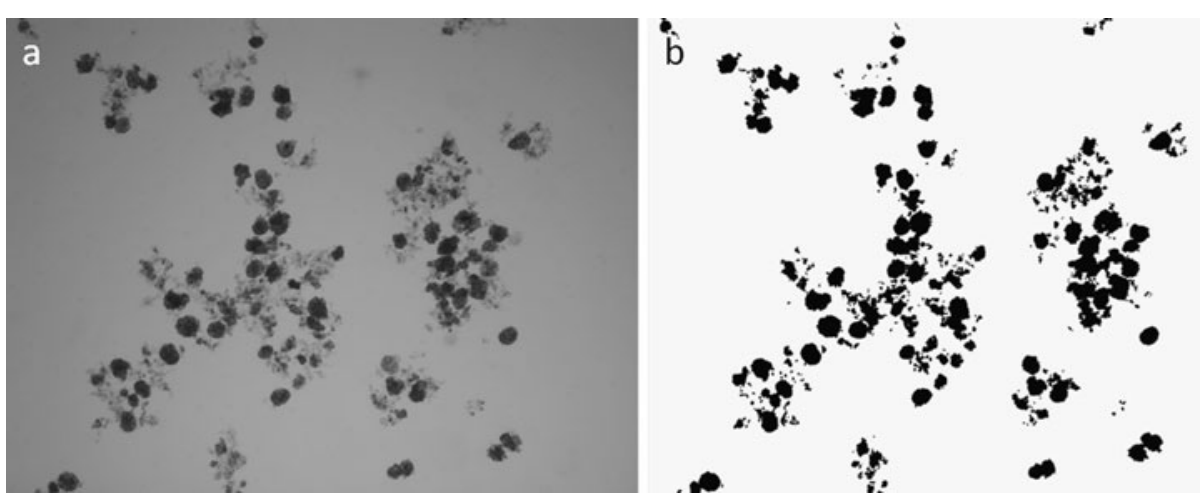
COD and $\mathrm{N}-\mathrm{NH}_{4}{ }^{+}$. The synthetic wastewater composition was constant in the organic matter and ammonium concentration. However, the fishery wastewater varied in organic matter and especially ammonium concentration. Changes in the wastewater composition could be attributed directly to the seasonal fishery processing step, which can influence the SBR performance. Thus, in order to reduce the possible disturbance of the biological system, the biomass adaptation to the wastewater composition and increased salt concentration was conducted before the SBR cycles. In order to compare synthetic and fishery wastewater results, in the second experiment with real fishery wastewater, $\mathrm{NaCl}$ was added only to obtain a final concentration of $0.5 \%$ to compare aggregated biomass results. Taking into account that the biomass used to treat fishery wastewater was already adapted to treat saline wastewaters, the effects of salt addition on biomass behavior and the use of real fishery wastewater were sought. Thus, biomass changes were due to salt addition and not because of the fishery wastewater composition.

Table 1 also shows the SVI and the turbidity at the end of the SBR cycle with synthetic and fishery wastewaters. These results revealed that SVI decreased and turbidity increased when $\mathrm{NaCl}$ was added. It was also stated that the effluent from the SBR treatment with fishery wastewater had higher turbidity. SVI values lower than $150 \mathrm{~mL} \mathrm{~g}^{-1}$ were achieved. Table 1 displays the total aggregates' area (TA) determined from the image analysis program for the overall biomass analyzed during this work. For synthetic wastewater, an increase (from 1.46 to $2.09 \mathrm{~mm}^{2} / \mu \mathrm{L}$ ) of the aggregates' area was detected when $\mathrm{NaCl}$ was added. Regarding fishery wastewater treatment, a decrease was attained ranging from 4.43 to $1.72 \mathrm{~mm}^{2} / \mu \mathrm{L}$. Table 2 shows three of the most important parameters determined from the final binary images: (i) equivalent diameter, (ii) number, and (iii) area. When the SBR was treating synthetic wastewater, there was an increase of the larger aggregates when $\mathrm{NaCl}$ was added (the aggregates' area increased from $3.9 \%$ to $22.5 \%$ ). However, an aggregate disruption based on the small aggregates' increase was also noticed (the number percentage increased from $64.2 \%$ to $84.1 \%$ ). Observing the results for fishery wastewater, a decrease of the larger structures was obtained (the aggregates' area decreased from $65.8 \%$ to $56.6 \%$ ).

\section{Discussion}

\subsection{Settling properties}

Microbial aggregates' stability in activated sludge and effluent quality are crucial in solid-liquid separation processes. Working with saline effluents causes cell plasmolysis and microorganism death due to the osmotic pressure increase. The existence of salt in wastewater reduces the populations of protozoa, resulting in higher dispersed bacteria contents, as most protozoa graze on bacteria, and lower sludge settling ability due to the fact that protozoa, on the course of their motion, break up the larger flocs. When the salinity of an effluent increases, the reduction of filamentous bacteria occurs (da Motta et al. 2001), decreasing also the mechanical integrity and structure of the aggregates (Moon et al. 2002). In the present work, the biomass structure response to a salinity increase was investigated based on the SVI and turbidity measurements. Usually, SVI values above the threshold limit for bulking phenomena $\left(150 \mathrm{~mL} \mathrm{gTSS}^{-1}\right)$ suggest this problem and poor sludge compaction characteristics (Jenkins et al. 2003). Table 1 illustrates SVI and turbidity values for synthetic and fishery wastewaters at the end of the SBR cycles.

Regarding Table 1, SVI values were found to decrease with $\mathrm{NaCl}$ addition for the synthetic and fishery wastewaters representing good settling properties. Even with the SVI decrease, the experimental data showed the turbidity increase for both synthetic and fishery wastewaters. One possible explanation for the effluent turbidity increase is a growth on the dispersed bacteria contents, as it is known that high $\mathrm{NaCl}$ contents lead to the decrease of bacteriagrazing protozoa. In fact, protozoa were not observed beyond the initial detection during the experiments without salt. Therefore, the control that protozoa exert on bacteria may be lacking, resulting in pinpoint flocs and dispersed bacteria, possibly created by the breakage of larger aggregates and leading to a low SVI and an effluent with high turbidity. Furthermore, filamentous bacteria, which are very important for the aggregates' structure, are also known to be highly sensitive to $\mathrm{NaCl}$ presence. It was already verified by several authors that with $\mathrm{NaCl}$ addition, the osmotic stress on microbial cells decreases the flocculation abilities (Moon et al. 2002; Campos et al. 2002). Hence, certain species of microorganisms may have been reduced, due to osmotic stress, leading to the release of their cellular components and thus increasing turbidity levels. The high turbidity levels may also have been provoked by high suspended solid contents due to the increase on the smaller aggregates' contents (pinpoint flocs) with low density properties. Hence, the proliferation of dispersed bacteria, cell rupture and liberation of intracellular contents, aggregates' structure changes, and lack of filamentous organisms are the most suitable explanations for the turbidity increase, with a larger impact for fishery wastewater treatment. In order to establish the true nature of the changes regarding the aggregated bacteria, a complementary study was performed for the biomass morphological assessment. 


\subsection{Image analysis evaluation}

The sludge used in this study was evaluated by the determination of image analysis parameters, subsequently used to monitor morphological changes closely related with the sludge settling properties. First, the total aggregates' area contents (Table 1) were determined in order to reveal the influence of $\mathrm{NaCl}$ addition, in the overall aggregated biomass, for both wastewaters.

Table 1 indicates how the aggregated biomass contents were disturbed when $\mathrm{NaCl}$ was added. Regarding the synthetic wastewater treatment study, salt addition led to an increase of the aggregated biomass contents. However, when the system was operated with the fishery wastewater, a clear decrease on the total aggregates' area was detected when $\mathrm{NaCl}$ was added. Furthermore, in both cases, the turbidity increase suggests that aggregates' disruption may have occurred releasing pinpoint flocs or free dispersed bacteria into the wastewater.

For a more thorough analysis, the aggregated biomass was divided into three classes, according to their equivalent diameter: below $0.01 \mathrm{~mm}$ (smaller aggregates configuring pinpoint flocs), between 0.01 and $0.1 \mathrm{~mm}$ (intermediate aggregates configuring small flocs), and above $0.1 \mathrm{~mm}$ (larger aggregates configuring normal aggregates). Morphological and structural parameters, such as the equivalent diameter, number and area distributions of each aggregate's class, were then evaluated for all classes to monitor the effect of $\mathrm{NaCl}$ contents on the aggregate size. Table 2 presents the aggregates' equivalent diameter, number percentage, and area percentage, respectively, for each aggregate's class regarding the synthetic and fishery wastewaters with $(0.5 \%)$ and without salt addition.

The results presented in Table 2 using synthetic wastewater showed that the $\mathrm{NaCl}$ addition was responsible for changes in the aggregates' morphological characteristics. Observing the increase on the $D_{\text {eq }}$, number and area percentages of the larger aggregates, it is possible to conclude that with $\mathrm{NaCl}$ addition, bigger aggregates were obtained corroborating the total aggregates' area results. Moreover, the obtained larger aggregates seem to be not fragile or open in structure. This explanation is based on the lower SVI values for the study with $\mathrm{NaCl}$ addition, revealing a more compact and denser structure. The $D_{\text {eq }}$ and number and area percentages of the intermediate aggregates decreased with $\mathrm{NaCl}$ addition. The reason can be partially due to the size increase of these aggregates into larger structures, thus shifting their contribution from intermediate to larger aggregates. A clear increase was attained for the small flocs when the system was operated with $\mathrm{NaCl}$ addition. An aggregate disruption, breaking up some flocs, is the most suitable explanation, releasing both pinpoint flocs and free dispersed bacteria into the bulk and thus increasing turbidity values. In conclusion, for the synthetic wastewater, a noticeable change in the aggregates' structure was found when $\mathrm{NaCl}$ was added. The growth of intermediate flocs led to larger and denser structures, and aggregates' disruption led to the increase of smaller aggregates' contents.

Regarding the fishery wastewater treatment, the decrease of the $D_{\text {eq }}$, number and area percentages of the larger aggregates seems to indicate a biomass deflocculation when $\mathrm{NaCl}$ was added. The same behavior was obtained by the intermediate aggregates, further emphasizing the deflocculation disruption scenario. These phenomena ultimately led to the increase in the number and area percentage of the smaller aggregates. The obtained turbidity results further corroborated the deflocculation phenomenon when the $\mathrm{NaCl}$ was added. The $\mathrm{NaCl}$ incited biomass disaggregation that, apart from originating pinpoint flocs, released a high amount of dispersed bacteria to the bulk, increasing the turbidity. Again, the elimination of protozoa communities from the process when $\mathrm{NaCl}$ was added further emphasized the dispersed bacteria and turbidity level increase. Due to

Table 2 Aggregates' equivalent diameter $\left(D_{\text {eq }}\right)$, number, and area for synthetic and fishery wastewaters with $(0.5 \%)$ and without $\mathrm{NaCl}$ addition

\begin{tabular}{|c|c|c|c|c|c|}
\hline & & \multicolumn{2}{|c|}{ Synthetic wastewater } & \multicolumn{2}{|c|}{ Fishery wastewater } \\
\hline & & $0 \%$ & $0.5 \%$ & $0.1 \%$ & $0.5 \%$ \\
\hline \multirow[t]{3}{*}{$D_{\text {eq }}(\mathrm{mm})$} & $<0.01 \mathrm{~mm}$ & $0.0094 \pm 0.0002$ & $0.0093 \pm 0.0002$ & $0.0067 \pm 0.0002$ & $0.0071 \pm 0.0001$ \\
\hline & $0.01 \mathrm{~mm}-0.1 \mathrm{~mm}$ & $0.0651 \pm 0.0031$ & $0.0576 \pm 0.0018$ & $0.0289 \pm 0.0004$ & $0.0257 \pm 0.0005$ \\
\hline & $>0.1 \mathrm{~mm}$ & $0.3259 \pm 0.0077$ & $0.4328 \pm 0.0126$ & $0.1855 \pm 0.0099$ & $0.1499 \pm 0.0042$ \\
\hline \multirow[t]{3}{*}{ Number (\%) } & $<0.01 \mathrm{~mm}$ & $64.2 \pm 0.5$ & $84.1 \pm 2.6$ & $66.7 \pm 0.6$ & $76.5 \pm 1.2$ \\
\hline & $0.01 \mathrm{~mm}-0.1 \mathrm{~mm}$ & $35.4 \pm 0.5$ & $14.7 \pm 2.8$ & $32.6 \pm 0.7$ & $23.4 \pm 1.2$ \\
\hline & $>0.1 \mathrm{~mm}$ & $0.3 \pm 0.2$ & $1.2 \pm 0.3$ & $0.7 \pm 0.1$ & $0.09 \pm 0.02$ \\
\hline \multirow[t]{3}{*}{ Area (\%) } & $<0.01 \mathrm{~mm}$ & $22.2 \pm 1.5$ & $35.2 \pm 1.7$ & $25.2 \pm 0.5$ & $41.9 \pm 2.2$ \\
\hline & $0.01 \mathrm{~mm}-0.1 \mathrm{~mm}$ & $73.9 \pm 0.2$ & $42.3 \pm 6.5$ & $65.8 \pm 1.6$ & $56.6 \pm 1.8$ \\
\hline & $>0.1 \mathrm{~mm}$ & $3.9 \pm 1.7$ & $22.5 \pm 5.9$ & $8.9 \pm 1.2$ & $1.5 \pm 0.3$ \\
\hline
\end{tabular}


the fact that pinpoint flocs do not settle at all, thus not contributing to the SVI determination, the combined reduction on the larger and intermediate aggregates' contents led to the increase of the observed SVI.

\section{Conclusions}

Image analysis information revealed that the addition of $\mathrm{NaCl}$ to the synthetic wastewater $(0.5 \% \mathrm{NaCl}$ experiment $)$ led to the growth of the intermediate aggregates into larger, and likely denser, aggregates, alongside some aggregate disruption. These phenomena were in accordance with both the observed sludge settling ability improvement (large and denser aggregates) and with the turbidity increase (aggregate disruption). Regarding the fishery wastewater, the addition of $\mathrm{NaCl}(0.5 \% \mathrm{NaCl}$ experiment $)$ led to a deflocculation phenomenon, of both larger and intermediate aggregates into pinpoint flocs and dispersed bacteria, ultimately leading to a turbidity increase. The release of pinpoint flocs and dispersed bacteria was found to be the most probable cause behind the observed turbidity increase.

\section{Recommendations and perspectives}

This study showed that image analysis is a valuable tool to characterize biomass changes from an activated sludge reactor. Depending on the wastewater nature, even when the composition is similar, different results are obtained, revealing that the results reached with synthetic wastewater cannot be extrapolated to fishery (actual) wastewater.

Acknowledgments The authors are grateful to the ALFA cooperation project BI-EURAM III (European Commission) between the Universidade do Minho and Universidade Federal do Rio de Janeiro and $\mathrm{CNPq}$ (Brazil) for the financial support for this work.

\section{References}

Amaral AL (2003) Image analysis in biotechnological processes: applications to wastewater treatment. $\mathrm{PhD}$ thesis, University of Minho, Portugal. URL: http://hdl.handle.net/1822/4506 (accessed 15 March 2010)

Amaral AL, Ferreira EC (2005) Activated sludge monitoring of a wastewater treatment plant using image analysis and partial least squares regression. Anal Chim Acta 544:246-253

Antileo C, Aspé E, Zaror C, Roeckel M, Urrutia H, Martí MC (1997) Differential bacterial growth kinetic and nitrification of fisheries wastewaters containing high ammonium and organic matter concentration by using pure oxygen. Biotechnol Lett 19 (3):241-244

APHA, AWWA, WPCF (1989) Standard methods for the examination of water and wastewater. American Public Health Association, Washington, DC
Campos JL, Mosquera A, Sanchez M, Mendez M, Lema JM (2002) Nitrification in saline wastewater with high ammonia concentration in an activated sludge unit. Water Res 36:2555-2560

Chu CP, Lee DJ (2004) Multiscale structures of biological flocs. Chem Eng Sci 59:1875-1883

Coelho MAZ, Russo C, Araújo OQF (2000) Optimization of a sequencing batch reactor for biological nitrogen removal. Water Res 34(10):2809-2817

da Motta M, Pons MN, Roche N, Vivier H (2001) Characterisation of activated sludge by automated image analysis. Biochem Eng $\mathrm{J}$ 9:165-173

Dinçer AR, Kargi F (1999) Salt inhibition of nitrification and denitrification in saline wastewater. Environ Technol 20 (11):1147-1153

Dinçer AR, Kargi F (2001) Performance of rotating biological disc system treating saline wastewater. Process Biochem 36(89):901-906

Ginoris Y, Amaral AL, Nicolau A, Coelho MAZ, Ferreira EC (2007) Development of an image analysis procedure for identifying protozoa and metazoa typical of activated sludge system. Water Res 41:2581-2589

Jarvis P, Jefferson B, Gregory J, Parsons SA (2005) A review of floc strength and breakage. Water Res 39:3121-3137

Jenkins D, Richards MG, Daigger GT (2003) Manual on the causes and control of activated sludge bulking, foaming and other solids separation problems. Lewis Publishers, Boca Raton

Kargi F, Dinçer AR (1999) Salt inhibition effects in biological treatment of saline wastewater in RBC. J Environ Eng ASCE 25:966-971

Lefebvre O, Moletta R (2006) Treatment of organic pollution in industrial saline wastewater: a literature review. Water Res 40:3671-3682

Li D, Ganczarczyk J (1991) Size distribution of activated sludge flocs. J Water Poll Control Fed 63:806-814

Li XY, Yang SF (2007) Influence of loosely bound extracellular polymeric substances (EPS) on the flocculation, sedimentation and dewaterability of activated sludge. Water Res 41(5):1022-1030

Mesquita DP, Dias O, Dias AMA, Amaral AL, Ferreira EC (2009a) Correlation between sludge settling ability and image analysis information using partial least squares. Anal Chim Acta 642(12):94-101

Mesquita DP, Dias O, Amaral AL, Ferreira EC (2009b) Monitoring of activated sludge settling ability through image analysis: validation on full-scale wastewater treatment plants. Bioprocess Biosyst Eng 32(3):361-367

Mesquita DP, Amaral AL, Ferreira EC, Coelho MAZ (2009c) Study of saline wastewater influence on activated sludge flocs through automated image analysis. J Chem Technol Biotechnol 84 (4):554-560

Moon BH, Seo GT, Lee TS, Kim SS, Yoon CH (2002) Effects of salt concentration on floc characteristics and pollutants removal efficiencies in treatment of seafood wastewater by SBR. Water Sci Technol 47:65-70

Moussa MS, Sumanasekera DU, Ibrahim SH, Lubberding HJ, Hooijmans CM, Gijzena HJ, van Loosdrecht MCM (2006) Long term effects of salt on activity, population structure and floc characteristics in enriched bacterial cultures of nitrifiers. Water Res 40:1377-1388

$\mathrm{Ng} \mathrm{HY}$, Ong SL, Ng WJ (2005) Effects of sodium chloride on the performance of a sequencing batch reactor. J Environ Eng 131 (11): $1557-1564$

Oren A, Gurevich P (1992) Microbial degradation of pollutants at high salt concentrations. Biodegradation 3(2-3):387-398

Panswad T, Anan C (1999) Impact of high chloride wastewater on an anaerobic/anoxic/aerobic process with and without inoculation of chloride acclimated seeds. Water Res 33(5):1165-1172 
Rene ER, Kim SJ, Park HS (2007) Effect of COD/N ratio and salinity on the performance of sequencing batch reactors. Bioresour Technol 99:839-846

Seixo J, Varela MH, Coutinho JAP, Coelho MAZ (2004) Influence of $\mathrm{C} / \mathrm{N}$ ratio on autotrophic biomass development in a sequencing batch reactor. Biochem Eng J 21:131-139

Souza SM, Araújo OQF, Coelho MAZ (2008) Model-based optimization of a sequencing batch reactor for biological nitrogen removal. Bioresour Technol 99:3213-3223
Uygur A (2006) Specific nutrient removal rates in saline wastewater treatment using sequencing batch reactor. Process Biochem 41:61-66

Uygur A, Kargi F (2004) Salt inhibition on biological nutrient removal from saline wastewater in a sequencing batch reactor. Enzyme Microb Technol 34:313-318

Wilén BM, Jin B, Lant P (2003) The influence of key chemical constituents in activated sludge on surface and flocculating properties. Water Res 37:2127-2139 